\title{
POSSIBILIDADES DA ANTROPOLOGIA FILOSÓFICA A PARTIR DA ANALIITICA EXISTENCIAL
}

Ernildo Stein*

SINTESE - No primeiro esforço de aproximação entre analítica existencial e antropologia filosófica, este ensaio procura estabelecer, em lugar de destaque, a idéia de compreensão do ser como elemento determinante do modo de serno-mundo do ser humano. Dessa primeira idéia decorrem então os dois teoremas de finitude: 0 círculo hermenêutico e a diferença ontológica. Temos, nestes dois pilares da filosofia hermenêutica, um novo modo de fundação e um novo modo de dar-se de todo ente. A diferença ontológica constitui o como (wie) tudo é acessível, vem ao encontro, mas ela mesma é inacessivel ao pensamento objetificador. Todo nosso modo de pensar e conhecer o ente passa por aquilo que é sua condiçăo de possibilidade. Mas todo, a dar-se nesse como (wie) é articulado no enquanto (als), no algo enquanto algo da estrutura da compreensão que é o modo de ser do Dasein, a dimensão hermenêutica do círculo do hermenêutico. A articulação desses dois teoremas da finitude, que são os elementos determinantes presentes em todo conhecimento humano, constitui o modo de ser e o modo primeiro de conhecer do ser do Dasein. A antropologia filosófica, a partir da analítica existencial, encontra nos dois teoremas da finitude seu estatuto filosófico.

PALAVRAS-CHAVE - Ser-no-mundo. Dasein. Analítica existencial. Antropologia filosófica. Compreensäo.
ABSTRACT - In an attempt to make a rapprochement between existential analytic and philosophical anthropology, this essay seeks to establish and highlight the idea of the understanding of Being as the determining element of the mode of Being-in-the-world of human beings. This leads us to two theorems of finitude: the hermeneutical circle and the ontological difference. We obtain, thus, from these two pillars of hermeneutical philosophy a new mode of foundation and a new mode of giveness of every being. The ontological difference constitutes the how (wie), as all is accessible, coming to our reach, and yet is itself inaccessible to objectifying thought. All our mode of thinking and knowing beings undergoes that which is its very condition of possibility. However, all that is given in this how (wie) is articulated in the as (als), in the something as something of the structure of understanding which is Dasein's mode of Being, the hermeneutical dimension of the hermeneutical circle. An articulation of these two theorems of finitude, the determining elements in every human knowledge, constitutes the mode of Being and the first mode of knowing Dasein's Being. Starting from existential analytic, philosophical anthropology finds thus in these two theorems of finitude its philosophical magnitude.

KEY WORDS - Being-in-the-world. Dasein. Existential analytic. Philosophical anthropology. Understanding.

* Pontificia Universidade Católica do Rio Grande do Sul - PUCRS. 
Para compreender a passagem da ontologia fundamental para o terreno das ontologias ou para apresentar como possivel a passagem da analítica existencial para a "metafísica da existência" (Heidegger), elemento básico para uma antropologia filosófica, é preciso empreender uma seqüência de considerações não apenas de ordem interpretativa, mas também de comparação com o trabalho de outros paradigmas alternativos da filosofia, sobretudo da filosofia do conhecimento.

\section{I}

Passo ao exame das várias etapas e perspectivas a serem aprofundadas.

Em Ser e tempo, Heidegger afirma: "A analítica do Dasein assim concebida permanece inteiramente concentrada na tarefa condutora da elaboração da questão do ser. Assim se determina seus limites." E o autor continua para então determinar o que a analítica existencial não pode ser e o que ela é, além da tarefa principal de que pretende dar conta: "Ela não pode querer dar uma completa ontologia do Dasein (grifo meu) que certamente deve estar constituída, caso algo assim como uma antropologia filosófica assente numa base suficientemente filosófica. Com vistas a uma antropologia possivel respectivamente sua fundamentação ontológica, a interpretação que segue oferece apenas alguns fragmentos, ainda que não inessenciais" (Heidegger, 1949, p. 17).

O filósofo reconhece, portanto, que faz sentido pensar numa ontologia fundamental, a possibilidade de uma antropologia filosófica. Mas naturalmente impõe distinções e tarefas preparatórias.

No começo da mesma obra, o filósofo nos avisa: "A prevalência onticoontológica do Dasein é por isso a razão pela qual ao Dasein lhe fica obstruído o acesso a sua constituição ontológica específica - entendida no sentido da estrutura 'categorial' - que lhe é própria. Dasein é para si mesmo onticamente, o mais próximo, ontologicamente o mais distante, porém, não estranho, pré-ontologicamente" (Heidegger, 1949, p. 16). Essa passagem descreve a dificuldade de análise nos três níveis - ôntico, ontológico e pré-ontológico, dos quais se ocupará Ser e tempo. Mas a dificuldade "não consiste num defeituoso equipamento de nossa capacidade de conhecimento ou falta, fácil de ser eliminada aparentemente, de um aparato conceitual adequado", mas a "interpretação deste ente está diante de particulares dificuldades que se enraízam no modo de ser do objeto temático no próprio comportamento tematizador" (Heidegger, 1949, p. 16).

Vistas a possíbilidade e as dificuldades que iremos enfrentar em nosso empreendimento, passemos para o exame propriamente dito.

\section{II}

A abordagem da primeira questão nos leva aos dois níveis que desde a metafísica de Aristóteles estão consagrados na ontologia - o nível do ente enquanto ente e o nível do ser do ente. A tradição metafísica aborda esses niveis de maneira objetivística. Ela trata os dois níveis como objetos a serem conhecidos. Os diver- 
sos autores, até a Idade Média, dão formas várias ao conhecimento deste objeto, mas sempre se examina o modo como são conhecidos, mas não se pergunta porque eles não são questionados enquanto são condições de possibilidade, razão pela qual Aristóteles permanece nos dois níveis.

Quando Heidegger introduz um ente privilegiado, o Dasein, aparece um novo nível de problematização do ser. O ser não se dá isolado como objeto a ser conhecido; mas ele faz parte da condição essencial do ser humano. O Dasein compreende o ser e por isso tem acesso aos entes. Sem essa compreensão nada se move no conhecimento, tudo permanece opaco. Mas assim, como pelo ser compreende os entes compreende-se também como ente; e não apenas isso. Compreende o ser porque compreende a si mesmo e se compreende porque compreende o ser.

Com esse terceiro nível o filósofo inaugura duas questões centrais na filosofia - o círculo hermenêutico e a diferença ontológica. A compreensão do ser nos leva a um caminho de duas mãos: o ser é, pela compreensão, a possibilidade de acesso ao ente: sem compreensão não há ente. Nosso acesso aos entes só nos é possivel porque o Dasein compreende o ser e não porque temos um outro fundamento para o conhecimento dos entes.

Assim o Dasein, pela compreensão, inaugura uma circularidade. Mas ela não é simples circularidade (no conhecimento, na lógica), mas uma circularidade que se dá pela compreensão. É, portanto, uma circularidade hermenêutica. O ser não funda o ente, nem qualquer ente funda o ser. A recíproca relação entre ser e ente somente se dá porque há o Dasein - isto é, porque há compreensão.

Aparentemente isso constitui uma simples afirmação; mas, na verdade, estamos aqui diante da introdução de um novo paradigma. Desde Aristóteles e a Idade Média, de um lado, e Kant de outro lado, não houve revolução igual. Sobretudo as consequiências da diferença ontológica são tão radicais que passam a nos oferecer a possibilidade de repensar os modelos de fundação de toda a tradição.

O círculo hermenêutico e a diferença ontológica são os teoremas que sustentam a teoria heideggeriana da realidade e do conhecimento, isto é a teoria da fundamentação do conhecimento. Mas as implicações da proposta de Heidegger devem ser confrontadas com outras soluções apresentadas na tradição.

A idéia de ser de Heidegger, na medida em que é vinculada com a compreensão do ser, caminho para pensar o ente, se revela como uma dimensão operatória: compreendendo-me no mundo e na relação com os entes compreendo o ser. Naturalmente essa compreensão do ser não é temática e deve ser explicitada. É precisamente essa explicitação que é a meta buscada pela analítica existencial ou ontologia fundamental, cujos teoremas se expressam no círculo hermenêutico e na diferença ontológica.

O ser heideggeriano torna-se o elemento através do qual se dá o acesso aos entes, ele é sua condição de possibilidade. Isso é a diferença ontológica. Como esta condição só opera através da compreensão pelo Dasein, pelo ser humano que se compreende, a fundamentação (condição de possibilidade) sempre se dá pelo círculo hermenêutico. 
A relação com o ser e com o modo de ser do Dasein não é uma relação com um objeto ou através de um sujeito, mas é uma relação que possibilita algo, o acesso aos entes.

$\mathrm{Na}$ tradição objetivista o ser é ainda pensado como objeto, ou como ente, ainda que o suprem, como na Idade Média. Mas esse objetivismo padece de uma estranha circularidade. Constrói-se uma teoria do ser, uma ontologia - e para esta operação se necessita de uma quaedam illuminatio divina - quando, no entanto, esse ser supremo (teologia) do qual se recebe essa illuminatio, é precisamente resultado da ontologia. É um círculo na argumentação que naturalmente não pode ser aprofundado aqui, mas é também um círculo na fundamentação

Heidegger dirá que assim Deus entrou pelos fundos na metafísica, ex post: Esta operação de contrabando da teologia na metafísica deu-se por causa da entificação do ser por efeito da ausência da diferença ontológica.

O modelo objetivista da fundamentação aristotélica é examinado por Ernst Tugendhat (Tugendhat, 1976, p. 24-34) que mostra, em suas análises, como Aristóteles entificou o ser por falta de uma teoria do significado. $\mathrm{E}$ o autor conclui que a ontologia pode ser compreendida como uma semântica formal Esta teria como função ser a base de como se dão os entes (Tugendhat, 1976).

Ainda que por trás da teoria da semântica formal esteja a influência de Heidegger, seu algo enquanto algo hermenêutico, Tugendhat não reconhece na questão do ser como Heidegger o coloca a questão da compreensão, por isso rejeita o círculo hermenêutico e não percebe a proximidade entre semântica formal e diferença ontológica. Manfred Frank (1991, p. 187) aproxima as duas, sendo o como da possibilidade dos entes, em textos notáveis, sendo o como da possibilidade inspirados em Tugendhat, mas suas análises também mostram os limites das hipóteses de Tugendhat.

Tugendhat permanece aristótelico e quer ler a questão do ser em Heidegger de modo aristotélico. É por isso que a questão central de Ser e tempo lhe escapa: aquela que liga o ser ao tempo, ou melhor que pretende apresentar a analítica existencial como ontologia fundamental, como base de qualquer futura ontologia, inclusive de uma metafísica da existência ou de uma metaontologia da existência ou de uma antropologia filosófica (Heidegger, 1978, p. 196-202).

A antropologia filosófica que Tugendhat tenta identificar em Ser e tempo é reconhecida por Heidegger como indicações (ver parágrafo 5), Mas ela propriamente só seria possivel, na observação do filósofo, após o êxito da ontologia fundamental. O tratamento mais especificado dessa questão é dada em sua obra póstuma no fim dos anos 20 (Heidegger, 1997 p. 10 a 47).

A analítica existencial, no entanto, é também uma crítica do modelo de fundamentação kantiano. Kant foge do objetivismo clássico mediante uma teoria transcendental do conhecimento. Passar do objetivismo para o idealismo transcendental não é um caminho fácil, dado que esta passagem, denominada de revolução copernicana, consiste numa perda de mundo. 0 modelo de fundamentação kantiano faz sentido; mas as exclusões que o filósofo foi obrigado a fazer para determinar um campo de conhecimento possivel trazem mais problemas que os 
resolvidos, quando se observa a sua distinção de fenômeno e coisa em si (noumenon). É que esta distinção é o primeiro a priori pressuposto, mas ele não entra na introdução das formas a priori que são propriamente o que produz a inteligibilidade do conhecimento. $\mathrm{O}$ transcendental kantiano não é apenas condição de possibilidade do conhecimento (da experiência) mas condição de possibilidade dos objetos da experiência. $\mathrm{O}$ idealismo transcendental perde o mundo e não o recupera mais. Kant o diz: "O escândalo da filosofia" é ainda não ter encontrado a ponte entre consciência e mundo (apud Heidegger, 1949, p. 201).

$O$ fato de Kant ter remetido a questão do ser e as metafísicas especiais, mundo, homem, Deus para o limbo da coisa em si permite a delimitação do mundo da causalidade, onde a consciência impõe as leis de funcionamento. É o mundo dos fenômenos regido pela causalidade que pode ser objeto de conhecimento. Deste conhecimento podem dar-se as condições de possibilidade. Prova-se de jure o que de facto é conhecido nas ciências empírico-matemáticas. Nos procedimentos kantianos, entretanto, foi construído um modelo de fundamentação que me parece irrecusável. Trata-se de estabelecer um elemento transcendente à consciência que funciona como a priori. Esse elemento não pode ser conhecido como objeto, mas entra operativamente em todo o conhecimento. A transcendência é constituída nesse processo.

Por um tal processo deve passar toda a filosofia que não quiser reduzir-se a um objetivismo ingênuo ou a um trabalho analítico que não consegue estabelecer nenhuma relação entre as palavras e o mundo. Justamente a grandeza da filosofia de Kant consiste em ter-nos ensinado que a inteligibilidade e mesmo a analiticidade em filosofia sempre depende desse elemento transcendente à consciência de que ela trata no esquematismo e que é a possibilidade da própria Crítica da Razão Pura (Ver Glauner F. 1998, p. 278-299).

\section{III}

É esse Kant que Heidegger tem presente em sua ontologia fundamental ou analítica existencial. O acesso ao ser que, em Ser e tempo, é colocado a partir da compreensão do ser e essa compreensão é dada a partir da compreensão que 0 Dasein possui de si mesmo, nos leva a termos que pensar criticamente a posição de Kant.

Heidegger compreende os limites da metafísica de modo diferente de Kant. Em primeiro lugar, ele não realiza uma distinção a priori que remete as metafísicas especiais a um espaço noumênico de onde elas não podem mais ser recuperadas para o conhecimento filosófico. Como segundo elemento a ser apontado temos o fato de a analítica existencial pela qual a questão do ser é levantada a partir da compreensão do ser pelo Dasein.

Abre-se aí um novo ponto de partida que se funda no círculo hermenêutico e introduz a diferença ontológica. Ser torna-se um conceito operatónio pela compreensão e a diferença entre ser e ente introduz um critério definitivo para se garantir a distinção entre ser e ente e impedir a entificação do ser. 
A ontologia fundamental examina o ponto de partida e já prepara a introdução do limite da metafisica. Assim desaparece propriamente a idéia de a priori da tradição e também a idéia de fundamento. A circularidade hermenêutica - compreensão do Dasein e compreensão do ser se articulam numa reciprocidade substitui o clássico modelo de fundamentação do conhecimento que se apresenta como relação sujeito-objeto. O Dasein como ser-no-mundo, introduz o ser-em como condição prévia de todo conhecimento.

É a partir do ser-em que se estabelece a receptividade e a espontaneidade da experiência que no desenvolvimento da analítica existencial são apresentados como sentimento de situação (afecção - Befindlichkeit) e compreensão (entendimento -Verstehen). É assim que o ser-em do ser-no-mundo torna-se o momento indepassável, o transcendente à consciência que funda o conhecimento. Mas esse fundar não é mais fundamento como na metafísica, que dissocia o fundante do fundado e dá ao primeiro um caráter apriori, de primeiro, de originário, de presença constante.

Assim, tanto objetivismo como o idealismo transcendental da tradição metafísica podem ser criticados e superados. Mas isso somente pode ser realizado a partir do conceito de cuidado (Sorge) que é o ser do ser-aí (Dasein) e da temporalidade (Zeitlichkeit) que é o sentido do ser do ser-aí. A tríplice estrutura do cuidado ser-adiante-de-si-mesmo já-ser-em, junto-das-coisas tem como determinantes os êxtases - futuro-passado-presente - que é o modo como o ser-aí se compreende, tem seu sentido.

O ser-aí se compreende desde o futuro, o ser-adiante-de-si-mesmo, que é já no presente o que traz o limite do poder-ser, a possibilidade do ser-para-a-morte. Essa possibilidade não é mais o que se opõe simplesmente à categoria da objetividade. Ela é o existencial que nos permite pensar a partir da compreensão, o modo de "fundamentação" pela circularidade. A possibilidade existencial vem substituir a constante presença do "eu penso" de Kant ou do "ser" da tradição.

Temos assim uma nova condição de possibilidade, desconhecida do modo de fundar da tradição. É por isso que Heidegger afirma, nas páginas ainda introdutórias de Ser e tempo: "Acima da efetividade está a possibilidade". Mas esta possibilidade não é mais uma modalidade, ela é um existencial. Se como diz Heidegger "Ser é o transcendens como tal", ele mesmo conclui que "cada explicitação do ser como transcendens é conhecimento transcendental" (Heidegger, 1949, p. 38).

Mas esse transcendental não é nem o transcendental do realismo objetivista nem do idealismo transcendental, mas se liga à "transcendência do ser do Dasein que é muito particular".

Sem entrarmos em mais detalhes podemos dizer que esse "ser do Dasein" já remete ao cuidado (Sorge) com sua tríplice estrutura e à temporalidade (Zeitlichkeit) como sentido do ser do cuidado. Trata-se, portanto, de uma transcendentalidade de caráter existencial. Esse conhecimento existencial é o da compreensão do ser que já sempre é operado em qualquer conhecimento do ente.

Temos assim em Heidegger, uma posição de fundação que se situa além do realismo e do idealismo no sentido clássico, mas que permanece um "idealismo" 
de caráter novo, "idealismo" da compreensão do ser que é o transcendente à consciência, isto é, temos que operar com ele sem poder explicitá-lo totalmente. Com a compreensão de ser se inicia para o ser-no-mundo uma estrutura de sentido que não se deixa objetivar, mas que é condição de qualquer conhecimento.

Com a análise realizada até agora conseguimos explicitar o elemento específico da fenomenologia, como ontologia fundamental: manter na questão do conhecimento um vínculo entre predicação e percepção, entre afecção e compreensão e afeç̧ão e inteligibilidade, para garantir nosso conhecimento, sem cair num realismo objetificador ou num idealismo cuja transcendentalidade nos faz perder 0 mundo e a possibilidade de lidar com o ser.

\section{IV}

Era preciso realizar o exame feito até aqui do modelo heideggeriano de fundação do conhecimento, em seus traços iniciais e decisivos e depois em seu desenvolvimento. Importava também situá-lo na tradição metafísica, comparando-o com os modelos de fundamentação objetivista de Aristóteles e de Tomás de Aquino, de um lado e de outro lado, com o idealismo transcendental de Kant.

Vimos as vantagens da proposta heideggeriana a partir de sua crítica aos modelos de fundamentação baseados no esquema sujeito-objeto. Vimos também que Heidegger, na busca do ponto de partida do conhecimento, estabelece como elemento inicial o ser-em do ser-no-mundo que é o modo como o Dasein desde sempre se dá.

Vimos ainda que tudo isso é acompanhado pela compreensão do ser. Pela compreensão do ser, o ser humano se compreende a si mesmo e compreende os entes. Nessa circularidade hermenêutica aparece a diferença ontológica sem a qual não se dá o acesso aos entes. Heidegger, pelo ponto de partida de Ser e tempo, preserva a questão do ser sem a qual não se pode pensar a metafísica, mas a questão do ser fica ligada ao modo de o Dasein ser-no-mundo.

Com sua ontologia fundamental Heidegger se afasta do modo tradicional de conceber as ontologias. A analítica existencial introduz na proposta da ontologia fundamental um conceito de temporalidade, para substituir o conceito de tempo objetificador com que lidam as ontologias tradicionais, fundamentando elas 0 conhecimento a partir do ser como presença constante.

Com sua fenomenologia hermenêutica transcendental Heidegger critica a fenomenologia subjetivista (objetivista) transcendental. Fez isso mostrando que 0 sujeito transcendental pressupõe um modo de ser-no-mundo do Dasein como abertura (Erschlossenheit), criticando a intencionalidade.

Com a analítica existencial Heidegger introduz uma distinção entre ela e a análise existencial. O filósofo dá ao existencial uma dimensão transcendental introduz com ela um limite - que é condição de possibilidade da compreensão do ser. Por essa razão, Heidegger procura separar cuidadosamente seu ponto de partida da antropologia. 
Uma análise histórica da obra de Heidegger teria que mostrar como o filósofo se vê em sua relação com a antropologia. Isso terá que ser feito em outra ocasião.

Aqui e hoje deve nos bastar ver a referência que Heidegger faz no parágrafo 5 de Ser e tempo, à antropologia filosófica, para então explicar isso na discussão da questão se é possivel trabalhar com certas propostas da analítica existencial para colocar o fundamento de uma antropologia filosófica.

Trata-se da passagem da página 17 (Heidegger, 1949):

"A analitica do Dasein assim concebida permanece inteiramente orientada na tarefa central da elaboração da questão do ser. Com isso se determinam seus limites. Ela não pode querer dar uma completa ontologia do Dasein, que sem dúvida, deve estar acabada para algo assim como uma antroplogia 'filosófica' poder encontrar uma base suficiente de sustentação. Na intenção de uma possível antropologia, respectivamente, de sua fundamentação ontológica, a interpretação que segue dá apenas alguns 'fragmentos' (Stücke) ainda que não inessenciais. Mas a análise do Dasein não é apenas a incompleta, porém, primeiramente também provisória."

Heidegger nos autoriza, portanto, a explorarmos as bases de uma antropologia filosófica, a partir da analítica existencial de Ser e tempo.

Mas para realizarmos a exploração das possibilidades de uma antropologia filosófica a partir da analítica existencial temos que definir, porque seria isso possivel a partir de Ser e tempo e não a partir da Metafísica de Aristóteles, da Crítica da Razão Pura de Kant, ou de outra obra clássica da tradição filosófica.

Teremos que introduzir em nossa análise uma questão que deve ser respeitada em qualquer iniciativa filosófica de retomar uma área daquilo que foi introduzido por Francisco Suarez na sistematização da escolástica e tomada como algo dado por C. Wollf: as metafísicas especiais, uma questão que poderia ter a seguinte formulação: pode-se partir de uma proposta de teoria do conhecimento ou de justificação, de uma teoria das relações entre consciência e mundo, Dasein e mundo, palavras e mundo, fundamentar uma teoria sobre um dos objetos das metafísicas especiais?

$\mathrm{Na}$ nossa investigação trata-se de averiguar a possível ampliação de certos aspectos da analítica existencial para uma antropologia filosófica.

Teríamos que saber primeiro se em Ser e tempo se trata de uma teoria do conhecimento. Penso que sim e que não podemos considerar apenas os parágrafos 43 e 44 como teorias do conhecimento e da verdade.

No entanto, Heidegger compreende a fenomenologia de modo diferente que Husserl. A maneira como Husserl argumenta na fenomenologia transcendental permite um certo paralelo com o criticismo kantiano. As diferenças são fundamentais, como mostra o artigo de Eugen Fink (1966) sobre fenomenologia que recebeu o elogio e a chancela do fundador da fenomenologia, mas as intenções divergem e não apenas sobre o que é transcendental. Mas Heidegger ao tomar como ponto de partida não as perguntas de Kant: Que posso saber? Que devo fazer? Que me é permitido esperar?, mas a questão que Kant afirma que se respondida seria a solução das três perguntas: Que é o homẹm?, desloca os problemas da teoria do conhecimento para a ontologia fundamental. 
Ao determinar o Dasein como ser-no-mundo e designar o ser do ser-aí de cuidado (Sorge) e o sentido desse ser a temporalidade, Heidegger deslocou o problema da teoria do conhecimento (fugiu dela como do vício e do cacoete do neokantismo) e terminou com as construções e os aparelhos transcendentais.

A pergunta pelo ser já desloca as questões clássicas do conhecimento. Falar delas então, como compreensão do ser e, por conseqüência, como compreensão do ser humano, impõe como caminho "A análise preparatória fundamental do Dasein". O ponto de partida leva Heidegger a dizer que em Kant falta a analitica existencial, o empenhar-se na resposta à pergunta: "Que é o homem?" e por isso não pode levar sua crítica às últimas conseqüências.

\section{V}

De uma teoria do conhecimento não se pode partir para desenvolver uma antropologia filosófica. Mas como a analítica não é uma teoria do conhecimento como Kant a concebia, ela pode dar indicações importantes (não inessenciais) para a base de uma antropologia filosófica.

Temos, portanto, a favor de uma busca dos fundamentos hermenêuticos de uma antropologia filosófica a própria referência de Heidegger no começo de Ser e tempo (parágrafo 5) e sobretudo todos os materiais que desenvolve na primeira parte de Ser e tempo. Poderíamos mesmo concluir que há elementos de uma antropologia filosófica na sua analítica existencial (parágrafos 9 a 41) que lhe permitem apresentar elementos do problema do conhecimento nos parágrafos 43 e 44 de Ser e tempo, invertendo-se nele a posição que em geral predominou na metafisica: o modo como o ser humano conhece nos dá indícios de como definir sua "essência".

Mas examinemos mais cuidadosamente esta frase: o modo como o ser humano conhece nos dá indícios de como definir sua essência. Se escutarmos o que assim vem enunciado com ouvidos metafísicos clássicos isso não faz sentido. Se no entanto percebermos que Heidegger se move na fenomenologia, e que seu modo de análise se alicerça na fenomenologia hermenêutica, recebemos indicações importantes.

"A interpretação ontológico-existencial é, diante da explicitação ôntica, não uma qualificação teórico-ôntica. Isso significa simplesmente: onticamente todos os compo rtamentos do ser humano são 'preocupados' (Sorgevoll) e conduzidos por uma dedicação (Hingabe) a algo. A 'generalização' é de caráter apriórico-ontológico. Ele não se refere a qualidades ônticas que surgem continuamente, mas a uma constituição ontológica que já sempre está como base. Esta constituição é o que primeiro torna ontolog icamente possivel que esse ente possa ser enunciado onticamente como cuidado. $A$ condição existencial de possibilidade (grifo meu) de 'cuidado pela vida' e 'dedicação' deve ser compreendido em sentido originário, é ontológico, como cuidado" (Heidegger, 1949, p. 199).

Concluindo o que Heidegger disse no que acima foi citado, temos a afirmação que nos traz com clareza a relação entre analítica existencial e antropologia: 
"A analítica do Dasein não visa, no entanto, uma fundamentação ontológica da antropologia, ela possui objetivo ontológico-fundamental” (Heidegger, 1949, p. 200).

E o autor encerra o nosso problema com a afirmação:

"A generalidade transcendental do fenômeno do cuidado e de todos os existenciais fundamentais possui, por outro lado, aquela amplitude pela qual é antecipado o chão (Boden) no qual se move qualquer explicitação ôntica e de visão de mundo quer compreendo o Dasein como cuidado pela vida ou carência ou seus opostos" (Heidegger,1949, p. 199-200).

E com relação a essa problematização, do ponto de vista da teoria do conhecimento, Heidegger afirma:

"A discussão dos pressupostos não enunciados das tentativas de solução apenas de teoria do conhecimento do problema da realidade mostra que isso deve ser retomado para dentro da analítica existencial do Dasein como problema ontológico" (Heidegger, 1949, p. 208).

\section{A isso pode ser acrescentado:}

"Se a expressão idealismo diz algo assim como compreensão daquilo de que ser nunca pode ser esclarecido pelo ente, mas que ele (o ser) é para cada ente o transcendental, então reside no idealismo a única e correta possibilidade de problemática filosófica" (Heidegger, 1949, p. 208).

É nesse contexto, ainda de Ser e tempo, que Heidegger conclui:

"O fato de o ente do modo de ser do Dasein (grifo meu) não poder ser concebido a partir da realidade e da substancialidade, nós expressamos pela tese: a substância do homem é a existência (grifo meu). A interpretação da existencialidade como cuidado (Sorge) e a delimitação dessa da realidade, não significa contudo o término da analítica existencial, mas deixam apenas aparecer, mais agudamente, as dimensões intrincadas de problemas na pergunta pelo ser e seus possíveis modos e pelo sentido de tais modificações: somente se é compreensão de ser, o ente enquanto ente torna-se acessivel apenas quando é ente do modo de ser do Dasein é possível compreensão do ser como ente" (Heidegger, 1949, p. 212).

Então a frase que escrevemos acima e na qual queríamos justificar a possibilidade de iniciar uma antropologia filosófica da analítica existencial, deve ser entendida no contexto que traçamos com estas citações de Heidegger.

A analítica existencial que parte da compreensão do ser, liga os dois teoremas: círculo hermenêutico e diferença ontológica ao contexto da justificação do conhecimento humano. E Heidegger procura mostrar que este conhecimento se situa no nível da condição de possibilidade. A analítica existencial como compreensão do ser não elaborou constructos a partir da consciência, da representação, da vontade, para então se afirmar que somente dados tais constructos temos uma explicação das condições de possibilidade do conhecimento.

$\mathrm{O}$ que se descreve, na ontologia fundamental são modos de ser que chegam ao conhecimento porque são formalizados em condições transcendentais rompidos com o modo concreto de ser-no-mundo e por isso seriam transcendentais. 
Heidegger procura mostrar que o compreender é essencialmente operativo. 0 ser humano se compreende, se explicita; desde sempre e isso se dá pela compreensão do ser. Se não se desse essa compreensão, não teríamos acesso aos entes, não seríamos o lugar onde os entes se dão. Somos esse lugar porque sempre já somos Dasein, o ser-aí ou o ser-o-aí (être-le-lá) como sugere Heidegger, numa carta dos anos 50 (Heidegger, 1957, p. 180): somos o "aí do ser" pela compreensão do ser.

Conhece, portanto, o ser humano, desde seu modo de ser; o como ele conhece é como ele é. Então chegamos à "essência" do ser humano examinando seu modo de conhecer originário que é existencial.

Mas o ser humano então não é como coisa, realidade, como substância, mas como existência, aspectos que já definimos quando analisamos esse modo de ser da estrutura do cuidado, no início. Por isso Heidegger afirma: "A substância do homem é a existência." Estamos, então autorizados a procurar uma base para a antropologia filosófica na a analítica existencial. Do modo fundamental de conhecer recebemos indícios para pensar o modo fundamental de ser do homem. Isso não poderia ser feito a partir do modelo aristotélico de conhecimento, nem do modelo kantiano. Em ambos os modos de fundar o conhecimento há algo conduzido por um objetivismo, realista em Aristóteles e idealista em Kant.

$\mathrm{O}$ vício já vem instalado pela maneira como se situa o problema do ser. Em Aristóteles é um objeto, em Kant é uma posição. De ambos se poderia avançar até uma concepção do tempo, apenas como presença, o tempo dos objetos. Em ambos o modelo sujeito-objeto se situa no caminho de uma constância no objeto ou na consciência e esta tem por ideal a absolutidade.

O modo como Heidegger situa a questão do ser, a partir da compreensão do ser, e desde a temporalidade do Dasein - do ser-o-aí, nos dá um novo modelo de fundação referido à circularidade e à diferença. Esse é o modelo da finitude.

A questão da fenomenologia hermenêutica mais difícil de explicitar é constituída pela finitude. Isso não resulta apenas do confronto direto que a questão da finitude representa com a metafísica. Mas temos dificuldade em situar corretamente uma filosofia afirmativa da finitude.

A fenomenologia hermenêutica já estabelece, no início da analítica existencial, o espaço da finitude como início campo para a filosofia, quando introduz a questão do ser a partir da compreensão do ser e define o Dasein como o ente que se compreende a si mesmo enquanto compreende o ser. Dessa posição inicial nasce a ontologia fundamental com seus dois teoremas, os teoremas da finitude: círculo hermenêutico e diferença ontológica.

Quando acima dissemos que o modo de ser - a essência - do homem recebe indícios do modo de conhecer - já o fizemos nesse quadro de pressupostos: a fenomenologia hermenêutica como pensamento da finitude.

Essência não é mais um conceito importado do aparato conceitual da metafísica. A distinção entre essência e existência é um par de conceitos da metafísica enquanto onto-teologia. Mas ela já vem problematizada desde Suarez e é assumida na sua condição de problema e não de solução por Kant. 
Heidegger, ao apresentar, portanto, a definição do homem - "a substância do homem é sua existência" - já trabalha com a consciência de que "essência" quando falamos desde a analítica existencial deve ser usada com muito cuidado. Não se trata mais de uma qüididade, nem da definição que resulta da determinação do gênero pela diferença específica - não se trata mais como vimos, há pouco, de uma simples generalização. Essência na fenomenologia hermenêutica passará a ser definida a partir de Wesen como manifestação fenomenológica do ser ou de um modo de ser.

A fenomenologia possui como modo de acesso o levar algo a mostrar-se assim como se desdobra em seu modo de ser, como se manifesta, como se dá. Se de todos os entes podemos falar do dar-se, do vir ao encontro, como diz Heidegger, como poderia a próprio ser humano ser determinado como os entes que no Dasein - o ser-o-aí - se dão? O Dasein não pode ser reduzido a uma essência que podemos determinar, como o faz a tradição metafísica, adicionando a elementos genéricos uma diferença específica, como os traços de animalidade comuns com outros animais especificados por uma racionalidade. Por isso o ser humano foge às determinações que uma natureza (essência) recebe pela diferença específica. De Waelhens afirma: "O privilégio da compreensão do ser se revela, com efeito, de um tal alcance que ele transforma inteiramente, e até os elementos subjacentes, o ente que dela é dotado. De modo que a investigação definitória dos elementos simplesmente comuns que este ente divide com os outros entes dos quais ele se distingue pelo seu privilégio essencial torna-se uma operação que não conduz a não ser a erros ou banalidades" (De Waelhens, 1961, p. 674).

Enquanto o ser humano é compreensão do ser ele se sustenta por dois teoremas: a circularidade hermenêutica e a diferença ontológica. Desse modo, enquanto Dasein - o ser-o-aí, o ser humano é o lugar da diferença ontológica, que é uma diferença entre ser e ente que nunca é inteiramente tematizada. Sendo o como do ser humano enquanto compreensão do ser "um exercício inesgotável de sua diferença." (De Waelhens, 1961, p. 678), ele jamais se estabelece como natureza ou essência como os outros entes. "Pelo fato de a compreensão do ser intrinsecamente ligada à finitude não existe visada exaustiva do ser e não há, do mesmo modo, compreensão do ser outra que aquela do homem" (De Waelhens, 1961, p. 678679).

O ser humano nunca pode dar-se a si mesmo um estatuto legitimador de sua possibilidade como efetividade. Ele é possibilidade como Heidegger o quer enquanto temporalidade em que predomina a futuridade, o poder-ser e não uma essência acabada. A fenomenologia hermenêutica quer se adequar, como método a esse modo de ser determinado pelo modo de conhecer (não temático). "A substância do homem é a sua existência" é um enunciado que agora parece fazer sentido. 


\section{Referências bibliográficas}

EUGEN, F. 1966. Studien zur Phänomenologie, 1930-1939. Den Haag, Martinus Nijhoff.

FRANK, M. 1991. Selbstbewusstsein und Selbsterkenntnis, Stuttgart, Reclam.

GLAUNER, F. 1998. "Der Transzentale Ort der Rede von Sprachtranszendens. Zu den Grundlagen einer Metakritik der sprachanalytischen Kantkritik". In Kant-Studien, ano, 89, caderno 3, Berlin, New York, Walter de Gruyter, p. 278-299.

HEIDEGGER, M. 1949. Sein und Zeit. Neomariuns Verlag, Tübingen.

. 1957. "Lettre a Monsieur Beaufret". In: Lettre sur L'humanisme. Trad. por Roger Munier, Paris, Aubier, 1957.

- 1978. Metaphysische Anfangsgründe der Logik. Frankfurt a. M. Vittorio Klostermann. 1997. Der deutsche Idealismus. Fichte e Hegel. Frankfurt a. M., Vittonio Klostermann.

TUGENDHAT, E. 1976. Einführung in die Sprachnalytische Philosophie. Frankfurt A.M., Suhrkamp.

WAELHENS, A. de. 1961. "Nature humaine et compréhension de l'être". In: Revue Philosophique de Louvain, Editions de l'Institut Supérieur de Philosophie, Tome 59, n. 64, nov, 1961, p. 672-682. 